\title{
Bloqueos de Nervio y Cirugía Ambulatoria. Aproximación infográfica.
}

\author{
Nerve Blocks and Ambulatory Surgery. An Infographic Approach. \\ https://doi.org/10.25237/carsach2020.01
}

Sebastián Layera $^{1}$, Daniela Bravo ${ }^{1}$, Julián Aliste ${ }^{1,2}$.

${ }^{1}$ Departamento de Anestesiología y Medicina Perioperatoria. Universidad de Chile. Hospital Clínico Universidad de Chile.

2 Departamento de Anestesiología y Medicina del Dolor. Clínica Las Condes.

Autor Corresponsal:

Dr. Sebastián Layera

Departamento de Anestesiología y Medicina Perioperatoria Universidad de Chile.

Hospital Clínico Universidad de Chile

Dirección: Carlos Lorca Tobar 999 oficina B222, Independencia, Santiago, Chile. Chile

Teléfono: +56229788221

e-mail: sebastianlayera@gmail.com

ORCID ID primer autor: https://orcid.org/0000-0001-5690-9609

Palabras claves:

Cirugía Ambulatoria, Anestesia Regional, Bloqueos de Nervio.

Key words:

Ambulatory Surgery, Regional Anesthesia, Nerve Blocks.

Abreviaturas: ATR: artroplastía total de rodilla, ESP: erector spinae plane (plano del musculo erector de la columna), LCA: cirugía reconstrucción ligamento cruzado anterior, ISAL: intoxicación sistémica por anestésicos locales.

Introducción 
Las siguientes infografías corresponden a los principales bloqueos de nervio periférico utilizados preferentemente para cirugía ambulatoria. En cada sección y para cada bloqueo se describen: el volumen de anestésico local sugerido, las indicaciones más frecuentes en el contexto ambulatorio y las precauciones que deben tomarse ante su ejecución. Para mayor detalle sobre la sonoanatomía, técnica de inyección y evidencia científica, se sugiere revisar Revista Chilena de Anestesia Vol. 49 Num. 1 pp. 14-78.

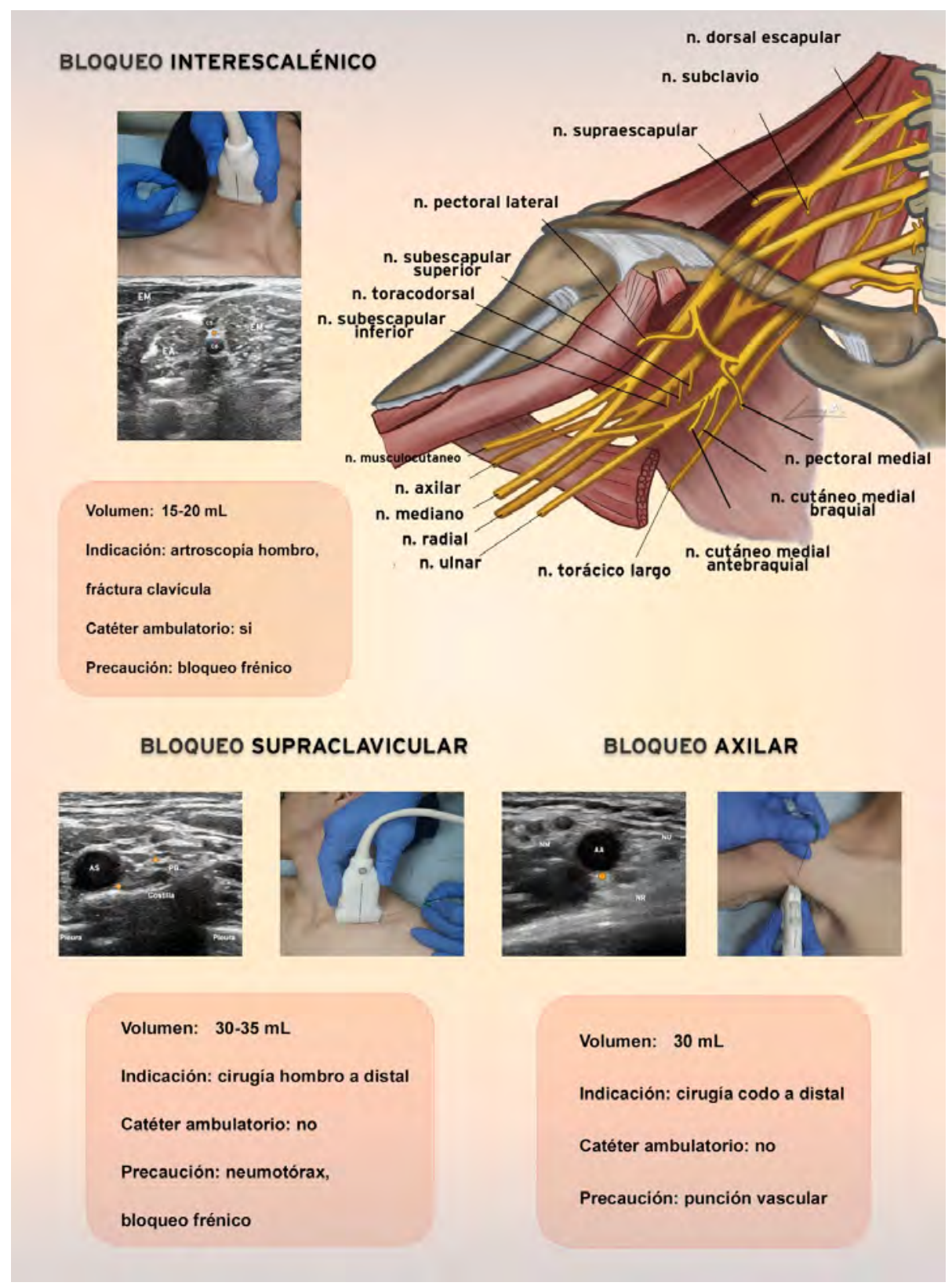




\section{BLOQUEO VAINA DE LOS RECTOS}
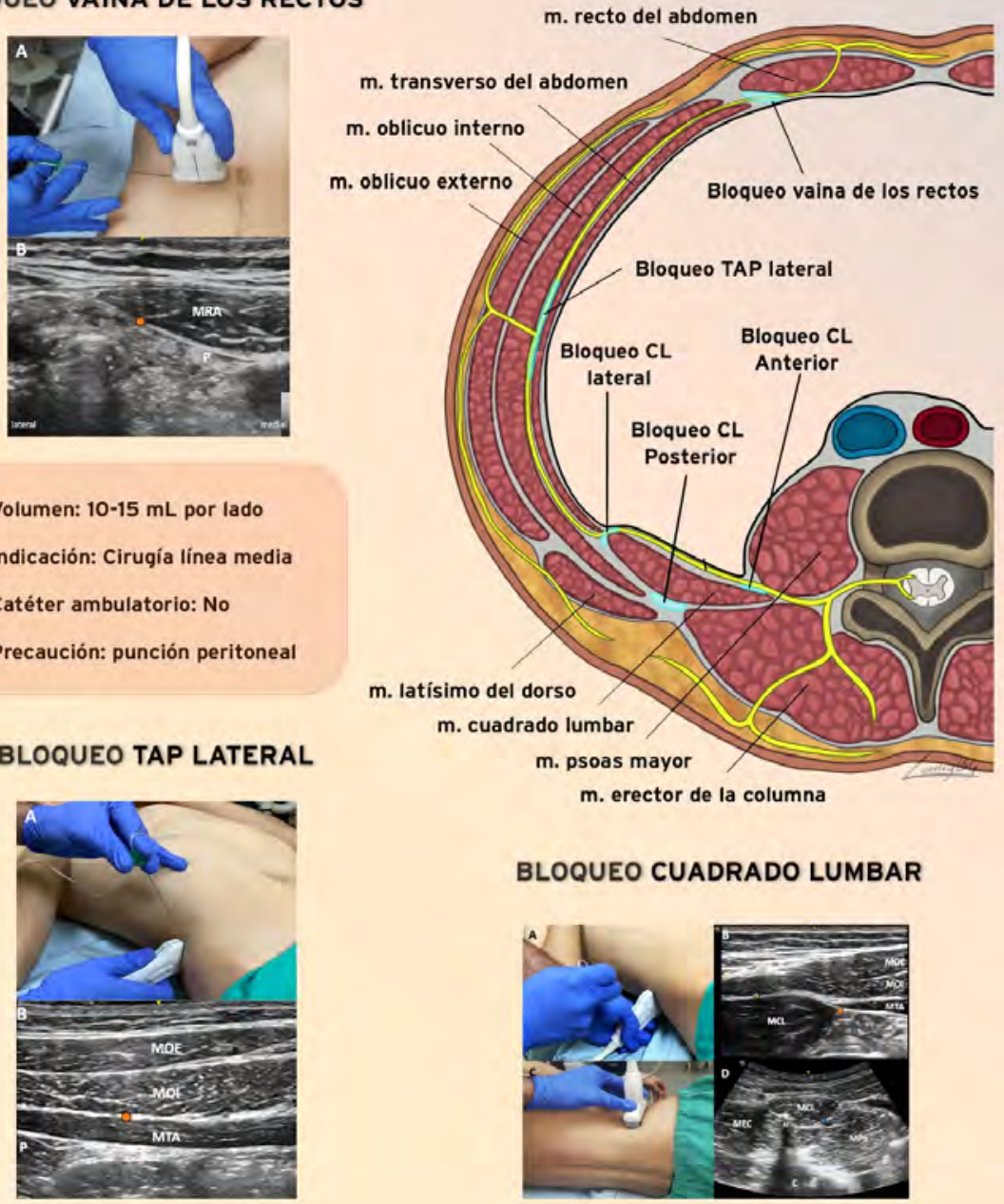

m. erector de la columna

Volumen: $10-15 \mathrm{~mL}$ por lado Indicación: Cirugía línea media Catéter ambulatorio: No

Precaución: punción peritonea

\section{BLOQUEO TAP LATERAL}

Volumen: $20 \mathrm{~mL}$ por lado

Indicación: Cirugía infraumbilical

Catéter ambulatorio: No

Precaución: ISAL

\section{BLOQUEO CUADRADO LUMBAR}

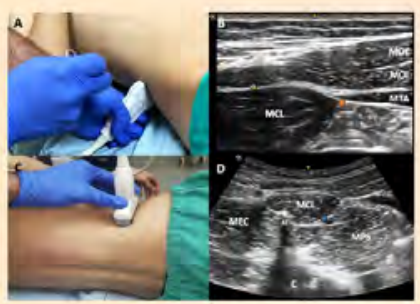

Volumen: $\mathbf{2 0 - 3 0 ~ m L ~ p o r ~ l a d o ~}$

Indicación: Cirugía infraumbilical

Catéter ambulatorio: No

Precaución: ISAL 


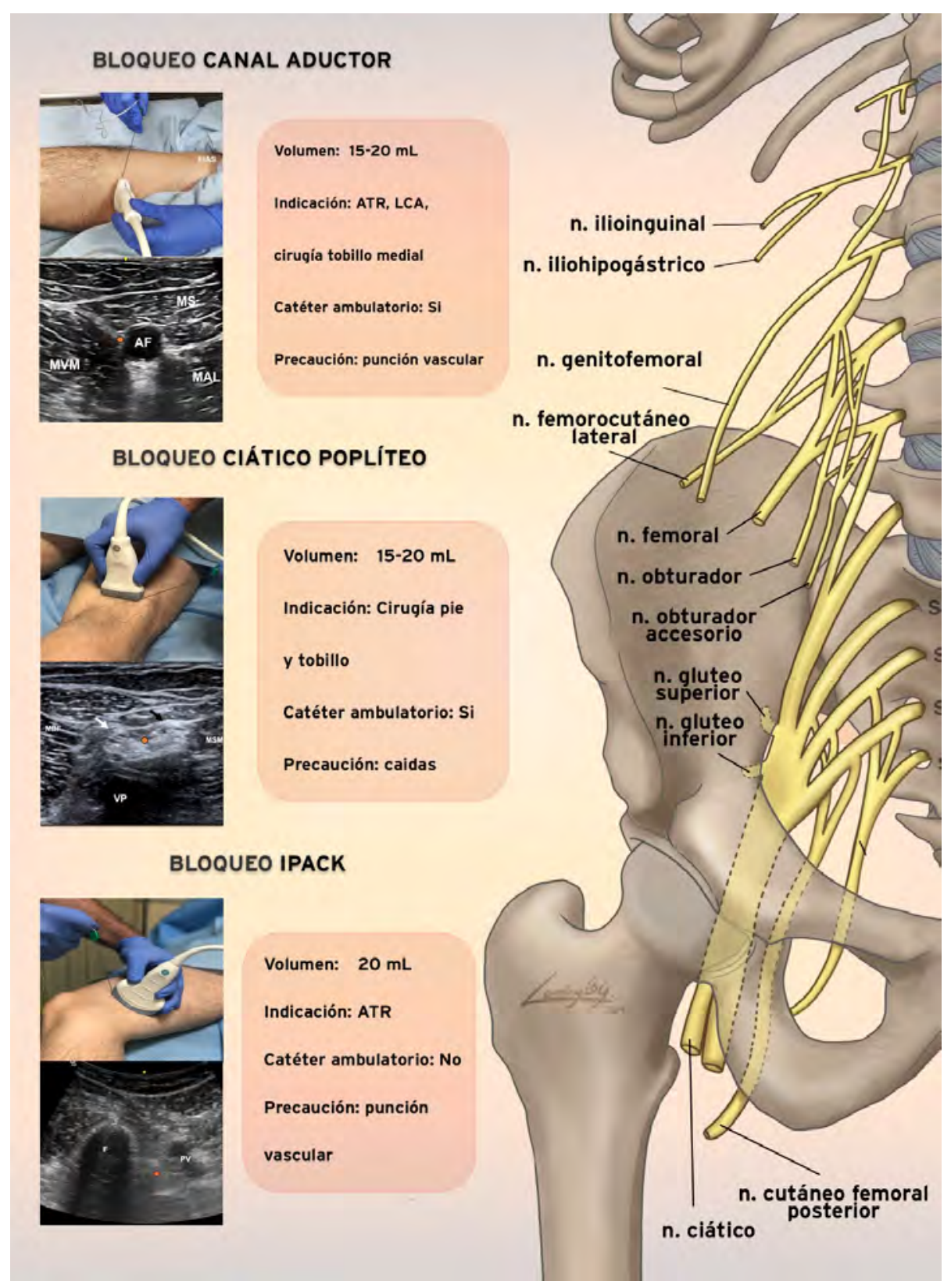

